The pulse was 72 , the respirations were 20 , and the temperature at 6 P.M. was $97^{\circ}$ and at 10 P.M. $99^{\circ}$. There were still frequent cough and slight perspiration at night. The patient's condition remained much the same until the 28th, when she had a further slight hæmoptysis, the temperature at 10 P.M. going up to $101^{\circ}$. The final note on the case was made on Jan. 2nd, 1908, as follows: "For the past three nights the patient has had slight hæmoptysis, the sputum not being much more than tinged with blood. She has also complained of headache which was at first frontal but for the last two days occipital. The condition seemed to be slightly relieved by phenacetin. At 6 P.M. on Dec. 31st the temperature was found to be 103. About 9 P.M. she vomited. On Jan. 1st the patient vomited seven times, the vomitus being mixed with slightly blood-stained sputum. No fresh pulmonary physical signs could be detected. At 1 P.M. to-day (Jan. 2nd) the girl began to cry out and to make a continuous loud groaning noise. The eyes became prominent and staring, the teeth were clenched, and the alæ nasi were working. At first the patient was quite conscious but later could not be roused. The eyes later became half closed and the corneal reflex was not obtainable. The right knee-jerk was glib; left knee-jerk normal. Kernig's sign was fairly well marked on both sides. No plantar reflex obtained on either side. Tache cérébrale was well given on the forehead. There was no retraction. The face was flushed and the skin acted freely. The lips were dry and there were sordes around the mouth. The patient died early on the morning of Jan. 3rd. Lumbar puncture was not performed."

A necropsy was performed by Dr. J. C. Ledingham, assistant pathologist to the hospital. The following is an abstract from the interesting post-mortem notes.

Thorax. - Left pleural cavity completely obliterated, the costal and pulmonary pleuræ being intimately connected by very strong adhesions. The right pleural cavity contained no fluid. The apex of the right lung was intimately adherent to the adjacent chest wall. The left lung was extremely congested in both upper and lower lobes. It was still slightly crepitant, however. At the apex of the right upper lobe there was a small caseous nodule with cicatrised lung tissue in the neighbourhood. Another small nodule (about 2 millimetres in diameter) was situated subpleurally near the lower border of the right upper lobe. The lower and middle lobes were quite crepitant and showed no congestion. Bronchial glands not enlarged.

Pericardium: The pericardial sac contained about two ounces of clear fluid. Heart muscle and valves appeared quite healthy. Just above the aortic valve were a few arterio-sclerotic patches. The foramen ovale was not completely closed, but the small semilunar opening still persisting was covered over on the left auricular side by a crescentic fibrous flap.

Abdomen.-Liver slightly enlarged and exhibited slight cyanotic induration. Spleen slightly enlarged and very soft and friable. Malpighian bodies not swollen.

Kidneys. - The left kidney was much smaller than the right and weighed $2 \frac{1}{4}$ ounces, the weight of the right kidney being $4 \frac{1}{2}$ ounces. The lower pole of the left kidney exhibited several cicatricial indentations having the appearance of old infarct formation. The right kidney was much congested.

Brain and meninges. - Over the pons, crura cerebri, medulla, and under surface of the cerebellum was a large quantity of yellow pus lying immediately under the pia mater. The purulent exudate did not extend up to the optic commissure and there was no trace of it along the Sylvian fissure. Both lateral ventricles were greatly distended with yellowish and slightly blood-stained grumous material. The floor of the right lateral ventricle was covered with minute ependymal hæmorrhages. No primary abscess formation could be found. There was no evidence of cerebellar tubercle. Both petrous bones were opened up, but no evidence of suppuration was found.

Bacteriological examination. -The pus from the meninges and lateral ventricles was found to contain enormous numbers of streptococci and pure cultures of streptococcus were obtained.

It is well recognised that in most cases of pulmonary tuberculosis the infection is a mixed one. Osler ${ }^{1}$ says : "Streptococci and pneumococci may be found in the sputa

1 Osler: Principles and Practice of Medicine, sixth edition, p. 336. and the former have been isolated from the blood." In an unsigned article in the 11 ospital, ${ }^{2}$ the results of "cultivations from the lung cavities in 100 cases of fatal phthisis" are given. Thirteen varieties of micro-organism were isolated. Amongst them streptococcus was present in 74 cases, pnenmococcus in 16, and an unidentified diplococcus in four. It would seem in the present case that the streptococci were carried from the pulmonary focus by the blood-stream to the base of the brain. The transitory enlargement of the thyroid was probably only the congestive condition associated with puberty and the onset of menstruation.

For permission to use the notes of the case I am much indebted to Dr. Reginald C. Jewesbury, assistant physician to the hospital.

City Hospital, Fazakerley, Liverpool.

\section{A CASE OF HEPATO-OMENTAL BANDS CONSTRICTING THE STOMACH.}

BY GEORGE A. HAWKINS-AMBLER, F.R.C.S. EDIN. YATE HONORARY SURG EON AND GYNTCOLOGIST TO THE BOOILE BOROUGH HOSPITAL.

THE patient, a female, aged 22 years, was first seen at the out-patient department of the Bootle Hospital, when she gave the following history. She had suffered from anæmia at the age of 16 years, but had recovered. A year later she was attacked with pain in her stomach, which commenced sometimes before, sometimes three or four hours after, meals. When the pain came on before food she would have an intense desire to eat ("hunger pain") and feel a "sinking sensation at the stomach." Food seldom relieved, often increased, the pain, but she was eased by pressure or by holding up the stomach. The pain was sharp or griping in character and was referred to the right epigastric and hypochondriac regions and often to the back, and it was continuous until she lay dorvn, when, unless the attack was very severe, she was relieved, but a sore feeling would remain. The patient vomited at the onset of the pain, but rarely any blood, and only in small quantities, but the retching was severe. Vomiting was preceded by pyrosis. Nausea was frequent and was sometimes occasioned by the sight of food. Flatulence was a troublesome feature. There was no constipation and menstruation was normal. After some weeks of suffering she sought relief at various hospitals and became an in-patient on five different occasions for periods varying from two to 10 weeks, being treated as an out-patient in the intervals, and she was the interesting subject of clinical lectures on gastric ulcer and hysteria. While in hospital she could always eat well and she suffered very little pain or inconvenience, but on her discharge and resumption of work the symptoms returned with such severity as to make her life intolerable.

On examination the patient was found to be a slightly. built girl of medium height, fair complexion, anæmic, but not ill-nourished. She had good teeth and the heart, lungs, and pelvic viscera were normal. On distension of the stomach it was not observed to be enlarged and there was no splashing. Some tenderness was elicited by palpation at two fingers' breadth above and to the right of the umbilicus, but no pyloric thickening was observed. Examination of the gastric contents after a test meal revealed slight hyper chlorhydria. The kidneys and their excretion were normal Duodenal ulcer was suspected and the patient was kept in bed for four weeks on limited diet, from which meat and vegetables were excluded. After a few days of this treat ment she felt better; the pain and vomiting ceased and she enjoyed her food. Improvement continued, and after being. up and sitting out of doors for ten days she was transferred to the out-patient department. About a fortnight later, however, the patient was readmitted to hospital with a return of all her symptoms. She was so ill and was suffering so acutely that I determined to explore the stomach with a view of performing gastro-enterostomy if any definite lesion were discovered in that organ or the duodenum.

An incision was made in the middle line above the umbilicus, and the omentum was found to be firmly attached to the anterior abdominal wall; stretching from this some three or four thin bands of peritoneal adhesions passed over

2 Antistreptococcic Serum in Phthisis with Cavitation, Hospital, Jan. 18th, 1908. 
the stomach to the upper surface of the left lobe of the liver. These were divided between catgut ligatures, as were other bands that passed beneath the stomach and behind it. The stomach could then be carefully examined, but no thickening or abnormality could be discovered in it or in the duodenum and the abdominal wound was closed. The wound healed by the first intention and a month later the patient was sent to a convalescent home for a fortnight. She expressed herself as feeling well and perfectly free from pain or discomfort, able to eat ordinary food, and getting stouter. Months later the patient remained perfectly well and was able to do her work; she looked well, was stouter and of better colour, and had quite lost her abdominal pain and distress.

There were several points of interest in the case which in various particulars suggested the presence of duodenal ulcer. The patient was easy in bed and could take food and remain comfortable so long as she remained in the recumbent position. When erect the presence of food in the stomach weighed it down and by stretching the bands of adhesion dragged on the liver. This accounted for the relief which she obtained by holding up the stomach.

The case illustrates the curious origin of peritoneal adhesions. If they were from old gastric or duodenal ulcer, starting a local peritonitis-a doubtful supposition-one might expect to find a more definite history as well as, perhaps, some thickening of the walls of these organs to indicate the site of the lesion and adhesions of the viscera implicated. But the bands passed over and under the organ and had apparently no attachment to it nor any connexion with it. The stomach and duodenum appeared to be perfectly healthy, there was nothing to suggest the occurrence of perforation of their walls at any time, and there were no peritoneal adhesions to them; nor was there any floating kidney to drag peritoneal bands across nor any history of peritonitis, though the patient was carefully examined on this point, and her intelligence was above the average of that of most hospital patients.

Although, as in so many obscure abdominal cases, one cannot explain the origin of extensive peritoneal adhesions, the case, I think, illustrates the importance of exploring the abdomen in cases of prolonged, ill-defined gastric disturbance, and it is here recorded as an addition to the growing volume of cases that justify this practice.

I am greatly indebted to my house surgeon, Dr. H. J. Knox, for these careful notes of the case and for his assistance in the treatment.

Liverpool.

\section{A PLEA FOR THE USE OF ANTI- DIPHTHERITIC SERUM IN THE LARYNGITIS OF MEASLES.}

By A. A. WARDEN, M.D. GLasg. \& Paris, VISITING PHYSICIAN TO THE HERTFORD BRITISH HOSPITAL, PARIS.

THE gravity of diphtheria as a complication of measles was brought home to me in March, 1908, by the illness of an English girl, aged 16 years, temporarily resident in Paris and under my care. Although she recovered-thanks to tracheotomy and antitoxin-the lesson of the case seems obvious, namely, in the laryngitis of measles do not wait for a bacteriological diagnosis but at once inject antidiphtheritic serum. No doubt this thesis may admit of arguments both pro and con, but it is encouraging to note that authorities in these diseases recommend similar measures. A brief outline of the case referred to may be of some interest.

The patient had the usual preliminary symptoms of measles on March 4th, and on the following day, when I was called to see her, the rash was in full evidence. The temperature was exceptionally high-105० F.-but there were no pharyngeal, pulmonary, or other complications, and four days later the temperature fell to $99^{\circ}$. It immediately rose, however, and on the ninth day of illness it reached $104.8^{\circ}$, and symptoms of laryngeal obstruction appeared. For the next few days this seemed to yield to ordinary measures, the temperature remaining between $102^{\circ}$ and $103^{\circ}$, but on the thirteenth day of illness the obstruction became more definite. The right tonsil and the epiglottis were covered with a greyish exudate, strongly suggestive of diphtheritic membrane-a diagnosis that was afterwards confirmed by microscopic examination and by culture. A few hours after I had taken a swab of the exudate for analysis the child's condition became such that immediate action was necessary. The temperature reached $105^{\circ}$, the pulse was running at 130 and 140 , while the face was leaden in colour. The stridor as the air passed through the narrowed laryngeal opening and the deepening coma all contributed to make a picture not readily forgotten. The same night tracheotomy was performed and 40 cubic centimetres of Roux's serum as supplied by the Pasteur Institute were injected. 80 cubic centimetres were given on the following day in two separate doses, but for 48 hours, with the exception of a fall in temperature and a diminution of the respiratory obstruction, there seemed so little improvement that death was hourly expected. Imperceptibly a change for the better set in and by the twenty-fifth day convalescence was well established.

Another fact which shows the degree of toxæmia present is that at one time no more than four ounces of albuminous urine were passed in 24 hours. I pass over many interesting clinical details to return to my thesis that precious time was lost in not injecting serum as soon as laryngeal symptoms were observed. My reason was that laryngitis is a not uncommon complication of measles, whereas diphtheritic laryngitis must be altogether exceptional. "In former days," says Professor Comby, ${ }^{1}$ speaking of diphtheria attacking the larynx of a measles patient, "le croup des morbilleux était toujours mortel et la trachéotomie toujours infructueuse. Avec la serumthérapie les choses ont changé. On guérit beaucoup d'enfants atteints de laryngites diphtéritiques au cours de la rougeole, par la trachéotomie et surtout par le tubage." Trousseau's vast experience led him to expect no relief from operative measures once croup had attacked a child with measles. ${ }^{2}$

Conclusions. - 1. Laryngitis is a frequent complication of measles. 2. It is occasionally membranous in character. 3. Non-diphthericic membranous laryngitis in measles is exceptional. ${ }^{3}$ 4. In all cases of laryngitis in measles antidiphtheritic serum should be injected as soon as possible.

Paris.

\section{Clinital Altes:}

\section{MEDICAL, SURGICAL, OBSTETRICAL, AND THERAPEUTICAL.}

\section{NOTE ON THE RELATION OF THE CAPILLARY BLOOD-VESSELS IN PURPURA.}

By Willtam Osler, M.D. OXon. \& MCGild, F.R.C.P. LoNd., F.R.S.,

REGIUS PROFESSOR OF PHYSYC IN THE UNIVERSITY OF OXFORD.

THE view is gaining ground that in purpura a primary change in the endothelium, caused by some poison, permits of the passage of the blood corpuscles into the tissues. The hæmorrhagin of snake venom acts in this way (Flexner), and more recent studies suggest strongly that the essential lesion is in the capillary wall. ${ }^{*}$ In the following remarkable case a vascular change, the stimulus of a blister, prevented the occurrence of hæmorrhage in an area of skin universally affected.

On the 28th of February last I saw in Rome with Dr. G. Sandison Brock Mr. - aged 43 years, a robust Englishman, who was on his way home from Melbourne. He was rational, and told briefly the mode of onset, \&c. He was pulseless, the face, hands, and feet were deeply suffused, of a purple-red tint, but the skin was not purpuric. The conjunctivæ were infiltrated with blood. The skin of the arms and legs was thickly set with purpura, the spots being larger and more densely placed towards the trunk. The back and chest looked purple, partly from deep congestion, partly from fresh exudation. The skin of the abdomen was plum. coloured, a uniform hæmorrhage, except in an area of about

1 Comby : Maladies de l'Enfance, article Rougeole, p. 87.

2 See Dieulafoy, Pathologie Interne, vol. iv., article Measles, p. 77. Martin : Annoles de l'Institut Pasteur, 1892 p. 367.

4 See Pratt's article in Osler and McCrae's System of Medicine, A See
vol. iv. 